\title{
El sindicalismo
}

en el derecho español: Modelo, problemas y perspectivas ( $y$ II)

Tres parecen ser los problemas mayores con que se enerenta la realidad sindical española, según se planteen desde los propios trabajadores, desde las estructuras sindicales, o desde el colectivo empresarial y la propia sociedad española. Las perspectivas de futuro se mueven entre tres escenarios posibles: el de unos sindicatos tuertes de empresa, la opción de sindica tos de industria 0 unos sindicatos de carácter político, en el peor sentido del término, con unos aparatos sindicales y unas cúpulas sindicales más superestructurales que reales, por excesivamente políticas.

En el articulo anterior se analizó el modelo sindical que se ha confor * mado a partir del derecho español y de las circunstancias de la transición. El modelo concreto de libertad sindical y de sindicatos más representativos desemboca en una serie de problemas y plantea unas posibles perspectivas que son las que se analizan en esta parte.

Antonio MARZAL FUENTES (*)

$\left(^{*}\right)$ Doctor en Derecho. Profesor de Derecho de ESADE (Barcelona) 


\section{Antonio Marzal Fuentes}

\section{Problema del modelo concreto de libertad sindical.}

Lo que acabo se sugerir en el apartado anterior no es irrelevante para el problema que propongo, y por ello lo vuelvo a tomar aquí como introducción de este apartado.

En el momento en que la Constitución ha establecido definitivamente el cuadro genérico de la libertad sindical, había dos posibilidades teóricas de presencia sindical en la empresa. 1) los Comités de Empresa, muy sindicalizados por el fenómeno de la práctica sindical clandestina durante el franquismo. Y 2) una institución nueva para esa práctica, imposible en el régimen anterior, y a la que el precedente italiano de la ley n. 300 de 1970 daba un cierto atractivo a sindicatos como los nuevos sindicatos españoles.

De hecho, hubo un vivo debate sindical, a finales de los 70 y principios de los 80 , sobre el interés, y las consiguientes preferencias sindicales, que se veían y centraban en una u otra fórmula. En la superficie del debate emergían ventajas teóricas y prácticas de uno u otro modelo. Pero en el fondo del debate lo que se ocultaba eran razones tácticas o estratégicas de los propios sindicatos, para disputarse el dominio del terreno reconfigurado por el pluralismo que les hacía competir a los unos con los otros. Apenas pasados los primeros años 80, ese debate se apagó. Posiblemente, la razón de ello fue la evolutiva configuración jurídica del concepto de "mayor representatividad sindical", que acaparó todo el interés de los sindicatos en sus luchas internas traídas por el pluralismo sindical, haciéndose inútil el anterior debate por la solución práctica que se dio a la construcción de aquel concepto. De ahí que le dé un apartado al análisis de este problema (1), antes de analizar en el siguiente apartado (2) el derecho español de las dos presencias de los sindicatos en la empresa. Dos presencias -y ésta es la tesis que yo defiendo- que formalmente son distintas, pero que informalmente se articulan muy estrechamente, haciendo de la segunda, de las secciones sindicales, sólo una segunda posibilidad dada a los sindicatos, o mejor aún, el reforzamiento de su presencia a través de los Comités en la empresa. 


\section{El problema de la mayor representatividad.}

1) El D. $3149 / 77$ de 6 de diciembre ya analizado distinguió entre una representatividad legal y una representatividad suficiente. La primera la tendrían todos los sindicatos constituídos conforme a la ley, y la segunda sólo la tendrían algunos, aunque no se dieran criterios jurídicos (de nuevo la primacía de la ortodoxia política sobre la jurídica) para determinar esa "suficiencia". En el fondo lo que alentaba en esa burda distinción inevitable, era la necesidad de replantearse el concepto de sindicatos más representativos. Un tema que en términos conceptuales claros y definidos sólo se abordará con la LOLS, que en su artículo 6.1 definirá "la mayor representatividad sindical" como "una singular posición jurídica a efectos tanto de participación institucional como de acción sindical" conferida a unos determinados sindicatos que puedan merecerla. El problema (al margen por el momento del tema de si la participación institucional no es una manera concreta de acción sindical) era el de buscar los criterios objetivables para acordar esa "singular posición jurídica" que es la esencia del problema.

2) Esos criterios se fueron diseñando a lo largo de una proceso de negociación interconfederal que comenzó muy pronto. El primero que trató de estos temas (el segundo habido en el tiempo después de los llamados Acuerdos de la Moncloa) fue el Acuerdo Básico Interconfederal de 10 de julio de 1979 y que fue firmado por la CEOE y la UGT. En él se decide que debe haber una "base representativa para ser interlocutores en la negociación", y se acuerda que tendrán esa "base" los sindicatos que consigan en las elecciones a Comités el $10 \%$ de los miembros de Comités o Delegados de Empresa.

El AMI (Acuerdo Marco Interconfederal) de 5 de enero de 1980, firmado también por la CEOE y la UGT, volvía a decidir el mismo criterio del 10\% para la calidad de interlocutor, independientemente de que hubiera que acudir a las condiciones establecidas por la ley (en alusión sin duda al ET que era ya un proyecto en discusión parlamentaria) para que los pactos concluidos con esos interlocutores tuvieran eficacia general. El mismo Acuerdo ( $y$ ahora a tono con el debate sindical a que arriba aludí y que entonces era vivo) acordaba la posibilidad de 


\section{Antonio Marzal Fuentes}

tener un Delegado sindical en las empresas de más de 250 trabajadores, si el sindicato que pretendía tener ese Delegado contaba con una afiliación sindical que supusiese el $15 \%$ por lo menos de la plantilla. Con ello se instituía por primera vez la posibilidad de creación de secciones sindicales por vía convencional.

3) La técnica legal del Estatuto de los Trabajadores del año 80 asumió lo conseguido en esos Acuerdos. Y en su art.87.2 exigía como legitimación de las partes, para dar eficacia general a los Convenios de ámbito superior al de empresa, el que los sindicatos, federaciones o confederaciones pactantes tuvieran el $10 \%$ de los miembros de los Comités o Delegados de Empresa del ámbito territorial y funcional de que se tratase. (Esta formulación fue cambiada en la Ley de Reforma del Estatuto del 84, precisamente para sustituírla por los criterios más precisos ya formulados por la LOLS, que ya había aprobado el Parlamento, aunque su vigencia estuviese aparcada ante el Tribunal Constitucional por los motivos más arriba explicados). Pero la filosofía del criterio de la "especial audiencia" "expresada en la obtención"' de un determinado $\%$ de representantes de los trabajadores (10\% a nivel estatal y $15 \%$ a nivel de comunidad autónoma, además de un determinado número absoluto para éstas, 1500 concretamente) conseguidos en las elecciones a Comités - Delegados de Empresa, que formulará luego más clara y precisamente la LOLS, queda ya fijado de esta manera. Y con él se operará para determinar los sindicatos a los que la ley acordará una singular posición jurídica que les capacite para determinadas funciones, la de estructurar la negociación pormedio de Convenios-Cuadro del art. 83.2, u otras más de detalle como la consulta para determinar los trabajos penosos de los jóvenes (art. 6.2), para implementar medidas aparentemente discriminatorias del fomento del empleo (art. 17.3), para la fijación del Salario. Mínimo Interprofesional (art. 27.1), para una política de ampliación o reducción de la jornada legal (34.5), etc., etc.

Finalmente, el ET apunta dos veces la posibilidad, acordada en los Acuerdos Interconfederales, de creación de secciones sindicales por vía negociada. La primera de un modo muy genérico, cuando el art. 61 preve otras formas de "participación en la empresa" distintas de las de Comités o Delegados que regula el ET. Y, segunda, cuando el artículo 87 
El sindicalismo en el derecho español:

modelo, problemas y perspectivas (yII)

legitima para negociar los convenios de empresa (al margen de las condiciones de eficacia), además de al Comité de Empresa, o en su caso, a los Delegados, "a las representaciones sindicales, si las hubiere".

4) La vía negociada posterior seguirá confirmando estos criterios con mayor o menor fortuna terminológica, dado lo impreciso del terreno a veces. El Acuerdo Nacional de Empleo, por ejemplo, de 9 de junio de 1981, además de llevar a Ios sindicatos más representativos a otros terrenos (el INSS, el INEM, el IMAC...) habla a veces de sindicatos representativos, otras de sindicatos más representativos, y hasta en alguna ocasión, en una posterior fe de errores, sustituyó curiosamente el concepto de representativos por el de firmantes en un asunto que trataba de posibilidades de vacaciones.

El Acuerdo Económico y Social (AES) de 9 de Octubre del 1984 (un Acuerdo tripartito, de naturaleza más ortodoxa politicamente que juridicamente) suponía ya los criterios fijos de la LOLS y aludía implícitamente a ella, cuando determinó que serían miembros de un "Consejo General de la Formación Profesional", que se creaba en el Acuerdo, aquellas "organizaciones empresariales y sindicales que tengan el carácter de más representativas con arreglo a la ley".

5) Esta ley era la LOLS aún no vigente entonces a pesar de la mayoría absoluta del Parlamento. Y esa ley, en sus artículos 5 y 7 establece tres clases de mayor representatividad, más allá de la representatividad propia de todo sindicato con respecto a sus miembros. 1) Una mayor representatividad a nivel estatal (el 10\%). 2) Una mayor representatividad a nivel de Comunidad Autónoma (el 15\%, y 1500 delegados como mínimo). Y 3) una especie atípica de "representatividad cualificada" en un determinado ámbito funcional y territorial, para aquellos sindicatos que, sin tener la primera o la segunda, hubiesen obtenido el $10 \%$ de los representantes en las elecciones a Comités y Delegados de empresa en ese ámbito prefijado.

El cuadro, sin embargo se hace algo más complicado, al introducir la ley una cuarta especie de "mayor representatividad" igual a la primera y a la segunda y llamada por la doctrina "derivada" " "por irradiación", aplicable a aquellos "sindicatos o entes sindicales, afiliados, federados 
o confederados a una organización" de ámbito estatal o de Comunidad Autónoma que tengan el carácter de más representativa. Esa "mayor representatividad derivada o por irradiación" no se extiende a la tercera may or representatividad, la que he llamado "representatividad cualificada". Las razones de estas diferencias son explicables a partir de los diferentes tipos organizativos sindicales, simples o complejos, que se conocen.

\section{Las consecuencias derivadas de la mayor representatividad sobre el modelo sindical.}

La anterior descripción pide un mínimo de reflexión crítica sobre el modelo sindical que indirectamente se consigue con la introducción de ese concepto de mayor representatividad por el Derecho español del Trabajo. Una análisis que podría dejarse conducir por la línea sugeridora de una libro de Fourastié, "L'invité inatendu'. Todo proyecto, según Fourastié, tiene consecuencias reales que no han podido preverse pero que se dan por la lógica de las cosas que existen. Estas consecuencias son "el invitado inesperado", el invitado con que no contabas y que sin embargo se presenta a la cena que se ha preparado para otros, y que cuenta tanto o más que los otros en ella.

Desde esta perspectiva el análisis de los criterios para fijar en la práctica el concepto de mayor representatividad podrían ser "invitados inesperados" que nos cambian (deseándolo ocultamente o no) el modelo sindical proyectado. Sintetizo en tres puntos mis reflexiones.

a) El criterio de la audiencia de un sindicato para concederle o negarle una "mayor representatividad", es un criterio común, razonable y dificilmente discutible, porque va implicito en el concepto mismo de mayor representatividad para el que se crea.

b) Otra cosa es el criterio concreto para fijar esa mayor audiencia. El Derecho español no ha recogido criterios más objetivos como el de la historia e implantación cultural de un sindicato, o el de su número de afiliados, por difíciles de constatar en los hechos sin controversias. Y consiguientemente se ha reducido al criterio del número de Delegados o miem- 


\section{El sindicalismo en el derecho español: modelo, problemas y perspectivas (yII)}

bros del Comité de empresa conseguidos en las elecciones convocadas para ello, que es un criterio menos objetivo (teóricamente no se trata de elecciones sindicales, y además un gran número de trabajadores está excluido de jure o de facto de ellas), pero que tiene la ventaja de su constatación más fácil y, por consiguiente, de su mayor comodidad en la práctica.

c) Pero ello no quita para que la fijación de ese criterio no desnaturalice muy sensiblemente en la práctica la institución (en este caso, los Comités y Delegados de Empresa) que se utiliza como instrumento de medida de aquella "especial audiencia". Y esto es lo que ha sucedido en el Derecho español del Trabajo. Los Comités de Empresa se hacen sólo el símbolo de la fuerza de la presencia de los sindicatos en la empresa. En vez de ser una representación unitaria de los trabajadores de la empresa para la defensa de sus intereses en ella, los Comités son sólo la mediación del poder sindical en la empresa. Con ello, el viejo debate sindical sobre si apoyar a los Comités de Empresa o a las Secciones sindicales de Empresa dejaba de tener sentido. Y por eso mismo dejó de ser debate aquí, en los primeros años 80 , cuando el tema de la mayor representatividad sindical quedó zanjado en las líneas del actual derecho. Pero, al mismo tiempo, y a efectos del análisis, deja sin demasiado sentido el problema que aún me queda por analizar de las dos formas de presencia de los sindicatos en la empresa.

El problema de las dos formas de presencia: descripción y significado. La descripción de las formas de presencia.

Con lo anteriormente dicho, que anticipa una interpretación valorativa, la descripción de esas formas de presencia tiene un interés muy relativo.

En términos formales, cualquier manual hace esa descripción, y no tiene mucho interés repetirla con detalle. Basta recordar que el ET da el perfil jurídico de los comités de empresa/delegados de personal, y que la LOLS configura jurídicamente la institución de las secciones sindicales y la de los delegados sindicales.

Sólo ofrece algún interés descriptivo, para los efectos de mi interpre- 
tación, recordar que la LOLS distingue tres clases de secciones sindicales:

1) Las secciones sindicales simples, constituidas por "los trabajadores afiliados a un sindicato" "en el ámbito de la empresa o centro de trabajo" (art. 8.1.a)). Estas secciones sindicales no quedan configuradas más que como una expresión más de la libertad sindical, sin un tratamiento jurídico específico.

2) Las secciones sindicales que se merecen, a juicio del legislador, un tratamiento singular, y que a su vez es doble son:

2a) "Las secciones sindicales de los sindicatos más representativos y de los que tengan representación en los comités de empresa y en los órganos de representación que se establezcan en las administraciones públicas o cuenten con delegados de personal" (art. 8.2). Estas secciones sindicales tienen especificos derechos. Además del derecho "a la negociación colectiva en los términos establecidos en su legislación específica" (art. 8.2.b) en relación con el ET art. 87), tienen derecho a que la empresa les facilite "un tablón de anuncios que deberá situarse en el centro de trabajo y en lugar donde se garantice un adecuado acceso al mismo de los trabajadores" (art. 8.2.a), precisamente para facilitar su acción de sindicatos en la empresa, y concretamente "la difusión de aquellos avisos que puedan interesar a los afiliados a los sindicatos y a los trabajadores en general" (art. 8.2.a)

2b) Las secciones sindicales de centros de trabajo a) que ocupen "a más de 250 trabajadores" (en realidad, a pesar de la mala formulación, que ocupen un número de trabajadores de 250 en adelante) y b) que se constituyen con presencia en los comités de empresa o en los órganos de representación que se establezcan en las administraciones públicas" (art. 10.1).

La representación de esas secciones viene ostentada, "a todos los efectos, por delegados sindicales elegidos por y entre (los) afiliados (al sindicato del que se trate) en la empresa o centro de 
El sindicalismo en el derecho español:

modelo, problemas y perspectivas ( $y$ II)

trabajo". Y el número de delegados de cada sección viene configurado de una doble manera:

A) Legalmente: a) un sólo delegado en el caso de que los sindicatos de que se trata "no hayan obtenido el $10 \%$ de los votos en el comité de empresa o en el órgano de representación en las administraciones públicas" (art. 10.2.párrafo 4), y b) de uno a cuatro delegados en función del tamaño de la plantilia (1 de 250 a 750 trabajadores, 2 de 750 a 2000,3 de 2001 a 5000 , y 4 de 50001 en adelante) (art. 10.2. párrafo 3).

B) Convenientemente, el número de delegados sindicales de las secciones que llegan al 10\% de la representación en los comités de empresa y órganos de representación en las administraciones públicas podría ser distinta, es decir más amplio, "bien por acuerdo bien a través de la negociación colectiva" (art. 10.2. párrafo 1), pues la fijación legal del número sólo cuenta "a falta de acuerdos específicos al respecto" (art. 10.2. párrafo 2).

Finalmente el artículo 10.3 explicita los derechos específicos de esta última clase de secciones sindicales. Lo más decisivo es que tienen las mismas garantías que los comités de empresa (art. 10.3 párrafo o, en relación con el ET artículo 68), y, entre ellas, -lo más interesante en la práctica- "el crédito de horas mensuales retribuidas (...) para el ejercicio de sus funciones" (ET art. 68, e)), crédito de horas que son acumulables por pacto en uno o varios, siempre que no se rebase el número de horas del total de los créditos (ET. art. 68, e)). La LOLS, por otro lado, imbrica notablemente a los delegados sindicales con los comités de empresa y órganos de representación en las administraciones públicas (art. 10.3.19, $2^{\circ}$ y $3^{\circ}$ ).

\section{El significado juridico-político de las dos formas de presencia.}

Por la descripción hecha ya se ve que las dos formas no son, en términos reales, tan distintas.

En efecto, las dos formas de presencia son: 
a) en gran parte coincidentes, es decir, por un lado, dos formas de presencia montadas sobre los mismos principios de un cierto poder de los sindicatos en la empresa, y, por otro, dos formas de presencia articuladas la una sobre la otra, es decir, la sección sindical sobre el comité, que sería así la matriz del poder sindical en la empresa. Al menos las secciones sindicales que más cuentan en la realidad porque llegan a tener delegados sindicales con específicos derechos.

b) dos formas de presencia que, en cuanto coincidentes, y analizadas con respecto a la estructura de los sindicatos en cuanto referidos a la totalidad de los trabajadores (a la generalidad de la profesión o de la clase), sólo serían un mero instrumento exterior del reconocimiento de los sindicatos como superestructura política del sistema, al margen de la afiliación, de su real implantación en la vida cotidiana de la sociedad, y hasta de su aceptación, en términos de afección o desafección, por parte de ésta. En un cierto sentido se podría decir, exagerando y a partir de las pautas de la vida política americana, que las dos formas de presencia de los sindicatos en la empresa serían sólo, por obra y gracia del concepto jurídico de "mayor representatividad sindical" construído por el derecho español, un enorme aparato electoral para conseguir la cuota de poder político de los sindicatos en el sistema general de poderes, jurídicos o fácticos, de la actual sociedad española.

c) De ser esto así, mi tesis de partida (o hipótesis de trabajo) podría matizarse en las conclusiones siguientes, que planteo más como interrogaciones, o como tendencias a las que habría que estar atento, que como conclusiones definitivas de un modelo hecho.

1. Los sindicatos que salen del franquismo son sindicatos configurados, conformados, modulados en torno a la empresa, o, mejor, en torno a la práctica sindical de empresa. Pero en cuanto sindicatos clandestinos, (es decir, forzados a la clandestinidad), esperaron de la libertad sindical el milagro en cuya espera vivieron, y que muy rápidamente, con la constatación de una desafección general por ellos, no se produjo.

2. E1 nuevo derecho español, una vez afirmada la libertad sindical, configuró jurídicamente a los sindicatos en torno a la empresa, primero 
El sindicalismo en el derecho español:

modelo, problemas y perspectivas $(\mathrm{yII})$

con Comités de Empresa, cuya naturaleza sindical reforzó, y luego con Secciones Sindicales, que amplificaron la dinámica sindical de aquéllos.

Pero al mismo tiempo, al hacer depender, con la afirmación de la libertad y pluralidad sindicales, el poder de influjo político de los sindicatos sobre la estructura social del concepto jurídico de "mayor representatividad", la presencia o presencias de los sindicatos en la empresa se hacían, inconscientemente y dada la desafección general en que éstos pronto se movieron, el instrumento único y práctico para conseguir ese poder.

3. De ahí la aparición de una doble estructura, una de la empresa, aparentemente más bien sindical, social y real, y otra de fuera de la empresa, más bien política y superestructural, que hace dudar de la verdadera naturaleza del modelo sindical nacido del nuevo Derecho español del Trabajo.

Por un lado, se puede decir que los sindicatos españoles son, ante todo, sindicatos de empresa, al modo anglosajón pero con espíritu italiano, nacidos de la empresa, actuantes en ella y orientados hacia ella, confirmándose las tendencias surgidas con el franquismo.

Pero, por otro lado, y a partir del peso que se le de al modo cómo se ha formado el concepto de "mayor representatividad" y a la vista de la desafección y de la escasa afiliación de que los sindicatos son objeto, también se podría decir que los nuevos sindicatos surgidos en el nuevo Derecho español del Trabajo son una pura superestructura política de clase, que recibe su poder de una cierta implantación electoral en las empresas, convertidas en colegios electorales de otro juego.

Hay datos para defender una y otra tesis, sobre todo si se olvidan los matices y se exagera algo la línea directriz de una u otra tendencia. De hecho habría una tercera tesis pesimista, que a veces emerge en ciertos analistas políticos, según la cual los sindicatos españoles serían ambas cosas a la vez, pero a costa de ser poco lo que realmente son o debieran ser, sindicatos. Una tesis o una propuesta que podría tener un cierto sentido, si se la articula con el tema hoy general y candente de la crisis sindical moderna en las sociedad industrial postmodema. De ser verdad esta tesis, la tragedia de cuarenta años de franquismo se expresaría con toda su fuerza. Cuando los sindicatos españoles podían serlo, no les dejó 
Antonio Marzal Fuentes

el sistema. Y cuando el sistema les dejó, ya no podían serlo. No es la única manifestación de esa tragedia.

\section{Parte II: Problemas y perspectivas.}

Con ello y a partir de una discusión analítica sobre la interpretación del modelo existente, he entrado casi inconscientemente -y algo dramáticamente, lo reconozco-, en los problemas del sindicalismo español tal como se está asentando en las prácticas sindicales. Pienso por lo tanto que ha llegado el momento de dar por acabada la crítica interpretativa del modelo, para entrar directamente en el recuento de sus problemas, y explorar desde ellos las perspectivas de futuro a medio plazo.

\section{Los Problemas.}

Acepto de entrada que el recuento de problemas que pretendo -de ahí la brevedad desproporcionada de esta parte- es un recuerdo más interrogativo que analítico; y que su intención es la de incitar a la reflexión y al diálogo ante una realidad que se está haciendo, más que la de establecer un diagnóstico fundamentado sobre exploraciones indiscutibles.

Pues bien, desde esta perspectiva que es ahora la mía, tres me parecen ser los problemas mayores con que se enfrenta la realidad sindical española, según se planteen desde los propios trabajadores (1), desde las estructuras sindicales (2), o desde el colectivo empresarial y desde la propia sociedad española que, con la caída del franquismo, se ha abierto a la democracia (3).

1. Desde los propios trabajadores, el problema mayor me parece ser la desafección sindical reinante. Sean hoy las que sean las cifras reales de afiliación (que probablemente nadie sabe pero que ciertamente son muy bajas. La OCDE en 1985 daba un 5\%), lo que es poco discutible es que esas tasas subieran significativamente con la salida del franquismo, y luego bajaron, al cabo de poco tiempo, constantemente y también muy significativamente. En el actual momento esta tendencia no ha cambiado, ni parece probable que vaya a cambiar. La desafección parece ser la realidad dominante. 
Esto no sería necesariamente un problema en términos reales. En un país como el nuestro de escaso asociacionismo, la desafección sindical podría significar sólo que la gente no se apunta al sindicato, pero suponen que el sindicato está ahí y que su papel es importante, aunque sean "otros" los que lo hagan. Cuando el derecho distingue entre afiliación y audiencia, no hace más que reflejar ese lado de las cosas. La afiliación podría ser escasa, pero la audiencia grande. Si ésa fuera la realidad, esa realidad no sería irrelevante, pero tampoco sería un gran problema.

$Y$ sin embargo, personalmente yo creo que, en nuestro caso, esto es un problema. Y que la escasa afiliación, lejos de estar compensada por la audiencia, va acompañada en nuestro país por una escasa "credibilidad" de los sindicatos.

El trabajador español estaba habituado a un sistema (el franquista) donde eran fuertes las garantías de la relación individual del trabajo (el despido, por ej.) mientras eran nulas las garantías de la relación colectiva (la huelga o la negociación colectiva, por ejemplo). Y al salir del franquismo se ha encontrado que éstas últimas son plenas, mientras le quitan en la realidad (o así lo percibe él) las primeras. Y como él percibe que éstas son las que tocan directamente a su vida cotidiana, comienza a sentir, ya que no nostalgia del pasado, una positiva desafección por los sindicatos, basada en una escasa credibilidad de estos. Ese es el problema.

Ante ello, los sindicatos a veces se preguntan si no tendrían que cambiar y orientarse a un modelo de sindicato de servicios, en vez de el modelo reivindicativo que ha sido el suyo siempre. Personalmente pienso que esto es un grave error de diagnóstico. Pero es una confirmación, en negativo, del problema de la inanidad, o de la escasa fuerza e implantación real de nuestros sindicatos, no suplida por una supuesta y bien conseguida audiencia.

2. Segundo problema. Nuestros sindicatos tuvieron durante el franquismo un papel político muy importante, además de positivo. Pero, como en la biología, también en ellos se ha podido dar aquello de que la función crea el órgano o lo muta esencialmente. A mi juicio, los sindicatos tendrían que superar la nostalgia política del pasado, y entrar 
con decisión en la función moderna que un sindicato tiene en una sociedad democrática y desarrollada, la de contra-poder legítimo de otros poderes igualmente legítimos, llámense éstos empresarios o Estado. Aceptar la bipolaricad de la sociedad industrial, asumir que la tensión social es en la sociedad industrial, una tensión creadoray que el papel de los sindicatos es el de ser uno de esos polos y de serlo seriamente, sin negar la legitimidad del otro y sin dejarse robar su propia legitimidad, sería la tarea sindical del hoy, que debería alejarse tanto de la nostalgia de un pasado donde unos eran los buenos (ellos) y otros los malos (los otros), como de la utopía de un futuro, en el que, ganada la batalla política definitiva, se instalaba otro tipo de sociedad sin tensiones ni conflictos.

Yo no llego a decir que nuestros sindicatos crean hoy en ese papel político suyo que jugaron en otro tiempo, o que se comporten ahora de acuerdo con esas pautas. La propia experiencia de poder político que vivieron con el PSOE y la crudeza de la crisis económica de los primeros tiempos de la transición les ha ayudado a cambiar. Pero sí digo que de aquellos tiempos y de aquellos estilos les queda un gusto por el poder político, aunque lo llamen sindical, y de cumplir su papel a través de una mediación política directa. Mi interpretación del modelo como cúpula política superestructural apuntaba a eso. Pero si eso es real, es un problema mayor, para cuya solución los sindicatos españoles necesitarán más coraje del que suponen, y que tendrán que resolver como cuestión previa.

3. Tercer problema. Desde la propia sociedad, al menos en su forma de opinión pública, el segundo problema de la escasa identidad de la función sindical viene a veces agravado notablemente. El complejo de franquismo de unos (miedo a los sindicatos) y de antifranquismo emocional de otros (ingenuidad ante los sindicatos), hace a veces que la opinión pública trate a éstos como se trata a los niños o como si se tratase de gente incapaz de llegar a la edad adulta. Se les consiente acríticamente lo que no se les debería consentir (Por ejemplo, su implicación excesiva en los favores del poder público), y luego, consecuentemente, no se espera de ellos, ni se les exige, que cumplan su función de contra-poderes sociales y mucho menos que la cumplan seriamente. La percepción social que se tiene de los sindicatos es paternalista. Pero nuestros sindicatos no necesitan de nuestro paternalismo, sino todo lo contrario. Y eso es así, 
incluso cuando caen en la tentación de utilizarlo conscientemente y explotarlo a su favor. Con ello no hacen más que sacrificar el largo plazo por el plazo inmediato. Pero así no saldremos nunca de ese círculo vicioso.

Desde el lado de la sensibilidad empresarial, el comportamiento frente a los sindicatos no es muy diferente del que he descrito referido a la opinión pública. Quizás sea peor, por más cínico a veces. A veces el colectivo empresarial mima a los sindicatos porque no sabe cómo hacerlo. Pero a veces los mima como niños, para así neutralizarlos, y porque no se los toma en serio. Un grave error de cálculo, a mi juicio.

El colectivo empresarial es un poder y un poder legítimo. Un poder que, en contra de fáciles retóricas demagógicas, se ocupa y debe ocuparse de lo suyo (el beneficio, la expansión de la empresa). $Y$ un poder que, igual que cualquier otro poder, y también en contra de fáciles retóricas demagógicas, tiende a desbordarse y se desborda a veces cuando no encuentra límites. Lo que no revierte necesariamente en interés suyo.

Porque el poder empresarial, en una sociedad industrial desarrollada, no es un poder único por legítimo que sea. Es un poder en un sistema razonable de contrapoderes, de entre los cuales el contrapoder sindical es uno de los más relevantes y significativos. Dicho de otro modo, en una sociedad industrial el poder y el proyecto empresariales se definen por relación al poder y al proyecto de los sindicatos. Por eso los empresarios, en la sociedad industrial que tenemos, necesitan del poder sindical, como contrapoder claro y definido, canalizador del juego de intereses, que sólo así es operativamente posible. Y yo añadiría que necesitan de un poder fuerte, porque, si no, a largo plazo, se rompería el equilibrio sin el cual el juego no es juego, sino ineficacia además de abuso. Pero hoy por hoy, la situación no me parece que sea ésta, lo que agrava los muchos problemas de nuestro sindicalismo.

Hay empresarios que no lo ven así, pero confiesan que éste no es su problema sino el de los sindicatos. Y muchos de ellos se desesperan buscando el interlocutor que necesitan y no encuentran, esperando a un Godot que no llega nunca. Eso es también parte del mismo problema. 


\section{Antonio Matzal Fuentes}

\section{Las perspectivas.}

¿Cuáles son, a partir del recuento de estos problemas, las perspectivas de futuro?

Más que perspectivas, en las que yo no soy precisamente optimista, me gustaría describir algunos escenarios mayores de futuro. Tres en concreto, que están muy referidos a las soluciones técnicas que el actual derecho español del trabajo ha dado a algunos puntos.

1. Un escenario posible -y para mi, valorativamente, no sólo probabilísticamente, plausible- sería el de unos sindicatos fuertes de empresa. Que eso sea con la fórmula de las sección sindicales o que lo sea con la de unos Comités de Empresa y Delegados claramente sindicalizados, es una cuestión que me parece sólo relativamente interesante. La sindicalización de los comités es ya una tradición asentada, de uno u otro modo, en los países latinos. Pero el modo español de sindicalización me parece el peor. Porque hace de la empresa no el lugar de una actividad sindical de diálogo creativo y fecundo en el sentido de la bipolaridad de la sociedad industrial, sino el espacio escénico donde se juega otro juego, el de la consecución -muchas veces tramposa, en todo caso escasamente controlada- del título de sindicato más representativo. Se podría decir gráficamente que los sindicatos no están en la empresa, sino que pasan por ella para recoger otra cosecha, que es la que a ellos les interesa.

$Y$ sin embargo la tradición positiva conseguida en el franquismo fue la de unos sindicatos fuertes en la empresa. Una tradición que había que considerar como algo adquirido. Pero para que esta tradición reaparezca con fuerza respondiendo a una real necesidad operativa, para que al menos no se disuelva aún más como me parece ser el actual proceso, tendría que cambiarse en términos de política legislativa la construcción jurídica del concepto de sindicato más representativo de nuestro derecho. Y posiblemente el art. 83 del ET, volviendo al proyecto primitivo que se agotaba en el apartado 1, y repensando, si no borrando, los apartados 2 y 3 de ese artículo, añadido en la ponencia. Con ellos se pensaba razonablemente evitar una excesiva atomización de la negociación. Mi impresión es que esta estructuración jerarquizada de la negociación que 
El sindicalismo en el derecho español:

modelo, problemas y perspectivas (yII)

se añadió al proyecto, no ha evitado lo primero, y si ha desalojado a los sindicatos de la empresa como interlocutores claros y fuertes. Algo que no es deseable, a mi juicio.

2. Un segundo escenario se refiere a los sindicatos de industria. $\mathrm{Mi}$ simpatía por los sindicatos de empresa no agota a aquéllos en ésta. En la tradición continental que es la nuestra, la vida de los sindicatos de industria vivifica la acción sindical en la empresa. Y la afiliación sindical, que sigo pensando que es un bien, sólo cobra todo su sentido en aquéllos.

Pero para ello, el derecho del trabajo español debería replantear, en la línea del artículo 37.1. de la Constitución, la solución dada por el ET a los convenios de eficacia general. A mi juicio, la solución dada es el resultado acrítico de la peor herencia del franquismo, que perpetúa la eficacia general de los convenios en el nuevo cuadro de la sindicación libre. La nostalgia corporativa sigue, haciendo de los sindicatos más súbditos que ciudadanos. Pienso que es mejor la solución alemana, donde los convenios se aplican a los miembros de los sindicatos firmantes, aunque luego los empresarios los extiendan en la práctica a todos unilateralmente. Esa solución fomenta la afiliación, llena de sentido y de contenido activo la actividad negociadora, y hasta permite, en la mejor tradición continental, la libertad de los trabajadores frente a los sindicatos y los aparatos sindicales. Recuérdese, por ejemplo, la solución dada por el Tribunal Constitucional a la Disposición Adicional $5^{a}$ del ET. Por ley no se puede establecer la jubilación forzosa, pero sí podría hacerse, de acuerdo con el art. 37.1. de la Constitución, por convenio colectivo. Pero en este contexto, la eficacia general de los convenios estatutarios genera esclavitudes, si la sensibilidad de los sindicatos es menos social de lo deseable y más política de lo decente.

3. El tercer escenario se refiere a la pluralidad sindical y al carácter dominantemente político, en el peor sentido del término, de los aparatos sindicales, y de las cúpulas sindicales más superestructurales que reales, por excesivamente políticas.

Sé que la pluralidad sindical de hecho tiene sus inconvenientes. Pero también sé -y todo el mundo lo sabe-que, en nuestro contexto cultural, 
la pluralidad es un hecho. Intentar hacerla desaparecer o disminuir por métodos artificiales, me parece algo que falsea la realidad en vez de construirla. De hecho el modo como se ha hecho, es un método excesivamente político. USO lo sabe mejor que nadie, porque lo ha vivido en su propia carne, a pesar de su tradición sindical extraordinariamente viva.

Una cosa es el concepto de sindicato más representativo tal como lo concibió la OIT por sus necesidades de estructura, y otra el tratamiento jurídico que el derecho español del trabajo ha dado a ese concepto, y el perfil del concepto que con ese tratamiento ha conseguido. Yo no estoy en contra de los primero, y sí de lo segundo. Lo segundo me parece malo. Pero se ha conseguido implantar, por una vía indirecta, un modelo sindical, a mi juicio aberrante, que se quiso vehicular, en los primeros tiempos de la transición, por CC.OO. al alimón con Fraga. Unos sindicatos donde la afiliación no contase ("de nuevo cuño", los llamó Camacho si mi memoria no me traiciona) y donde lo que contase eran las cúpulas elegidas en unas curiosas elecciones sindicales, que supongo que unos y otros (Fraga, lo que Fraga representaba entonces, y CC.OO) esperaban poder ganar -de ahí, su interés en ese modelo- con medios políticos.

De hecho eso es lo que se ha conseguido, dejando ahora fuera a Fraga, con el perfil de sindicato más representativo de nuestro derecho y los monopolios excesivos que este le atribuye.

Urge cambiar eso, si queremos sindicatos vivos y operativos. Pero confieso que yo no soy optimista con respecto a este escenario. Más bien pienso que este modelo se reforzará aún más en los hechos. Con graves consecuencias para todos. También para los sindicatos. Yo diría incluso que especialmente para los sindicatos. Porque al fin de ese proceso, en el límite de esa función de límite cero, yo veo un panorama en el que habrá sindicatos sin sindicados. La cuadratura del círculo, dirán algunos con cierto distanciamiento. Yo digo otra cosa. Yo digo que si eso se da -y yo no querría que se diese- es la muerte del sindicalismo. 